\title{
Gene-Specific Universal Mammalian Sequence-Tagged Sites: Application to the Canine Genome
}

\author{
Patrick J. Venta, ${ }^{1-3,5}$ James A. Brouillette, ${ }^{1,3}$ Vilma Yuzbasiyan-Gurkan, ${ }^{2}$ \\ and George J. Brewer ${ }^{4}$
}

Received 19 Feb. 1996-Final 4 June 1996

We are developing a genetic map of the dog based partly upon markers contained within known genes. In order to facilitate the development of these markers, we have used polymerase chain reaction (PCR) primers designed to conserved regions of genes that have been sequenced in at least two species. We have refined the method for designing primers to maximize the number that produce successful amplifications across as many mammalian species as possible. We report the development of primer sets for 11 loci in detail: CFTR, COL10A1, CSFIR, CYP1A1, DCN1, FES, GHR, GLB1, PKLR, PVALB, and RB1. We also report an additional 75 primer sets in the appendices. The PCR products were sequenced to show that the primers amplify the expected canine genes. These primer sets thus define a class of gene-specific sequence-tagged sites (STSS). There are a number of uses for these STSs, including the rapid development of various linkage tools and the rapid testing of genomic and cDNA libraries for the presence of their corresponding genes. Six of the eleven gene targets reported in detail have been proposed to serve as "anchored reference loci" for the development of mammalian genetic maps [O'Brien, S. J., et al., Nat. Genet. 3:103, 1993]. The primer sets should cover a significant portion of the canine genome

\footnotetext{
${ }^{1}$ Department of Microbiology, College of Veterinary Medicine, Michigan State University, East Lansing, Michigan 48824-1314.

${ }^{2}$ Department of Small Animal Clinical Sciences, College of Veterinary Medicine, Michigan State University, East Lansing, Michigan 48824-1314.

${ }^{3}$ Genetics Program, Michigan State University, East Lansing, Michigan 48824-1314.

${ }^{4}$ Department of Human Genetics, The University of Michigan Medical School, Ann Arbor, Michigan 48109-0618.

${ }^{5}$ To whom correspondence should be addressed at Department of Microbiology, College of Veterinary Medicine, Michigan State University, East Lansing, Michigan 48824-1314.
} 
for the development of a linkage map. In order to determine how useful these primer sets would be for the other genome projects, we tested the 11 primer sets on the DNA from species representing five mammalian orders. Eighty-four percent of the gene-species combinations amplified successfully. We have named these primer sets "universal mammalian sequence-tagged sites" because they should be useful for many mammalian genome projects.

KEY WORDS: genome mapping; evolution; homology; polymerase chain reaction.

\section{INTRODUCTION}

Efforts have intensified in recent years to develop comprehensive genomic maps for many eukaryotic species using molecular techniques. Many of these efforts have focused on mammalian species, including human, mouse, rat, ox, sheep, pig, horse, cat, and dog (e.g., Buchanan et al., 1994; Dietrich et al., 1992; Ellegren et al., 1992; O'Brien, 1986; Serikawa et al., 1992; Weissbach et al., 1992; Winterø et al., 1991; Barendse et al., 1994; present report). For the nonhuman species, these projects should lead to more successful breeding strategies, both for selecting desirable characteristics and for removing genes that lead to various genetic diseases. Comparisons made between these genome maps should also lead to new insights on the mechanisms of chromosomal evolution (e.g., see O'Brien et al., 1993).

We are developing a comprehensive map of the canine genome, with our ultimate aim being to reduce the incidence of canine genetic diseases. In addition to developing random, highly polymorphic genetic markers (Type 2 markers), we are also developing markers for specific genes (Type 1 markers). An appropriate mix of these two types of markers should maximize our ability to map disease genes.

The traditional method for developing gene-specific markers, Southern blotting and cross-species hybridization, is very time-consuming, labor intensive, and limited in flexibility. This method has been the mainstay for developing gene-specific markers in most animal genome projects. There is a need to develop more efficient methods. This is particularly important for animal genome projects, where scientific resources are more limited. One method that has excellent potential is the cross-species polymerase chain reaction (PCR). This method has been used successfully for the study of a number of individual genes but has not been applied on a genomewide basis for the purpose of map development. To study a single gene, the cost associated with the failure of a few primers sets to amplify the correct target is negligible and new primer sets can be easily redesigned and synthesized. However, when primer sets are being designed for many genes, the cost for 
failed primers can become substantial, in terms of both time and other resources, so we have refined the design method to minimize this problem.

We describe here, in detail, 11 primer sets that can amplify genespecific targets of dogs and other mammalian species. Seventy-five additional primer sets are listed in the Appendixes. Because markers based on PCR primers are called sequence-tagged sites [STSs (Olsen et al., 1989)], we call these primer sets universal mammalian STSs (UM-STSs) because they should be useful for many mammalian genome projects.

\section{MATERIALS AND METHODS}

\section{DNA Isolation}

DNA from dog, human, pigtail macaque, horse, pig, rat, and mouse were isolated from various tissues by standard phenol-chloroform extraction methods (Sambrook et al., 1989). Goat DNA was kindly supplied by Dr. Karen Friderici, Michigan State University. DNA was purified by standard methods from a canine liver cDNA library (Clontech) and from a canine genomic DNA library (Clontech) after growing $1 \times 10^{6}$ phage in Escherichia coli strain LE392 (Murray et al., 1977) in liquid culture (Sambrook et al., 1989).

\section{Design of PCR Primers}

Primers were designed to genes where the intron-exon structure was known in at least one species and where the nucleotide sequence was known in at least two species (the "index species") that are not closely related. Tandemly duplicated genes known to have undergone gene conversion in any species were avoided. Primers were generally designed so that the amplified product contained an intron. We have followed the human gene nomenclature system (ISGN, 1987) for naming the canine genes. The 11 loci described in detail in this paper, and their protein products, are as follows: CFTR, cystic fibrosis transmembrane regulator; COL10A1, type $\mathrm{X}$ collagen, $\alpha_{1}$ chain; CSFIR, colony stimulating factor 1 receptor; CYP1A1, cytochrome P-450 1, $\alpha_{1} ; D C N 1$, decorin; FES, c-fes (feline sarcoma) protooncogene; $G H R$, growth hormone receptor; GLB1, $\beta$-galactosidase; $P K L R$, pyruvate kinase-liver, RBC form; $P V A L B$, parvalbumin; and $R B 1$, retinoblastoma protein. The Genbank Accession numbers or reference for the sequence of the two index species for each locus are as follows: CFTR, M55129 and M60493; COL10A1, X65120 and X65121; CSFIR, X14720 and K01643; CYP1A1 (Uchida et al., 1990), X04300; DCN1, L01125 and Z12298; FES, 
X06292 and J02088; GHR, Z11802 and J04811; GLB1, S59584 and M57734; PVALB, X63578 and M15452; PKLR, S59798 and M17088; and RB1, L11910 and M26391.

Primers were designed to highly conserved nucleotide sequences contained within coding regions. Additional considerations taken into account were degeneracy of underlying codons ( $\mathrm{Li}$ and Grauer, 1987), overall amino acid mutability of the primer region (Collins and Jukes, 1994), placement of the $3^{\prime}$ end of the primer with respect to amino acid mutability, and good standard design practices such as avoidance of primer-dimers. Conservation of amino acids within multigene families was also taken into account, when possible. Where unavoidable nucleotide mismatches occurred between the two index species, the primer sequence was designed to match exactly one of the two, which we then call the "primary" index species. GC-rich genes were generally avoided due to the amplification difficulties that can occur, even with exactly matching primers. Primers were $20 \mathrm{bp}$ in length on average. Each primer in a pair was adjusted to be of approximately the same annealing temperature (Breslauer et al., 1986). All sets of primer pairs were designed to have approximately the same annealing temperature as well, in anticipation of performing multiplex amplifications. It was not always possible to follow every rule for every gene, given the actual circumstances; however, the majority of the rules was generally applicable. Primers were synthesized by either the Michigan State University Macromolecular Structure Facility or the University of Michigan DNA Synthesis Facility.

\section{PCR Amplifications}

Correct design and syntheses of the primers were examined by amplifying the DNA from the primary index species. Standard buffer, nucleotide, and primer concentrations were $50 \mathrm{mM}$ Tris- $\mathrm{HCl}$ ( $\mathrm{pH} 8.3$ at room temperature), $50 \mathrm{~m} M \mathrm{KCl}, 1.5 \mathrm{~m} M \mathrm{MgCl}_{2}, 200 \mu M$ dNTPs, $0.1 \mu \mathrm{g}$ of each primer, and $0.5-1.0 \mu \mathrm{g}$ of target DNA in a $25-\mu \mathrm{l}$ reaction. Reactions were routinely boiled for $3 \mathrm{~min}$ prior to the addition of $2.0 \mathrm{U}$ of Taq DNA polymerase. Optimal cycling conditions for the amplification of canine genomic DNA were usually found by testing one of several sets of conditions in general use in the laboratory. Occasionally it was necessary to use "hot-start" conditions (Bassam and Caetano-Anolles, 1993) in order to get stronger, cleaner amplifications. The presence of an amplification product was determined by electrophoresis of a portion of the reaction on a $1 \%$ agarose TBE gel (TBE $=90 \mathrm{~m} M$ Tris, $\mathrm{pH} 8.3,90 \mathrm{~m} M$ sodium borate, $2.5 \mathrm{~m} M$ EDTA), followed by staining with ethidium bromide. 


\section{DNA Sequence Analysis}

The identity of each amplified canine gene was confirmed by "single-pass" direct sequencing of PCR products using Sequenase or Taq cycle sequencing kits (United States Biochemical Corp., Cleveland, $\mathrm{OH}$ ). The PCR products were gel purified with Qiaex (Qiagen Corp., Chatsworth, CA) or by elution from polyacrylamide gel slices (Bergenhem et al., 1992) prior to their use in the sequencing reactions. The canine sequences were visually aligned with the sequences of the other species used to design the PCR primers in order to verify the degree of sequence identity.

\section{RESULTS}

The primer sets for the various UM-STSs reported here are given in Table I and efficient amplification conditions for the canine genes are given in Table II. It is probable that these conditions could be optimized further (e.g., reduction in the time in each cycle). However, the conditions reported here were found to work effectively while minimizing the number of conditions that had to be examined. A representative gel showing amplification of the canine target DNA along with the human target DNA is shown in Fig. 1. The human target serves as a positive control for the amplification system because these primers were designed to match the human sequence exactly. The ability to quickly screen genomic and cDNA libraries for the presence of sequences is also demonstrated in Fig. 1. The genomic clones for GHR, COL10A1, and DCN1 [a very faint signal, stronger on other gels (data not shown)] are present in this particular canine genomic library. The presence of a decorin cDNA clone (encoded by the DCNI locus) in the canine liver cDNA library is shown by the presence of the 122-bp band; cDNA clones for GHR and COL10A1 are not present. The DCN1 PCR product from the cDNA library was sequenced and its identity confirmed (see Fig. 2). The human and canine genomic bands have different sizes for $G H R$ and $D C N 1$ because of the intron size differences. The size for the COL10A1 PCR product is the same between the species because an intron was not spanned, for this is the UM-STS. Although the PCR product bands in Fig. 1 are unique, a few UM-STS-species combinations sometimes contained one to several nonspecific amplification products. This is a minor problem with unique sequence primers, because it is almost always possible to deduce the correct band based upon staining intensity and on the similarity in size compared to the band of the primary index species.

The amplified products for all of the canine loci were sequenced to confirm their identity and the results are shown in Fig. 2. The degree of identity between the canine and the index species sequences for each locus is 


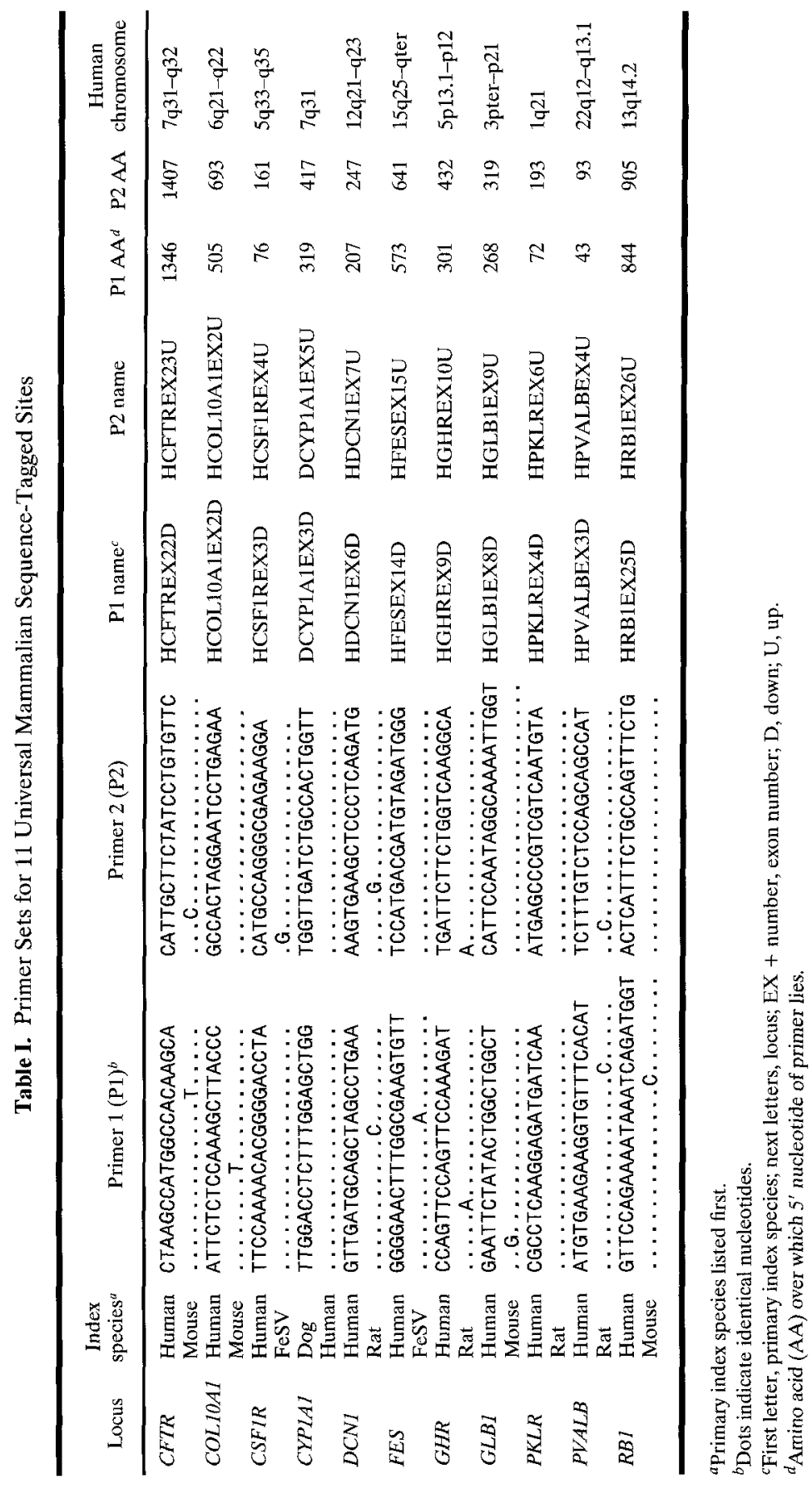


Table II. Amplification Conditions for Canine UM-STSs

\begin{tabular}{llllr} 
& & & \multicolumn{2}{c}{ Size of PCR product (bp) } \\
\cline { 4 - 5 } Locus & Temperatures $\left({ }^{\circ} \mathrm{C}\right)$ & Times $(\mathrm{min})$ & Human & Dog \\
\hline CFTR & $95,57,72$ & $0.5,1.5,4$ & 700 & 1000 \\
COL10A1 & $94,57,72(\mathrm{hs})^{a}$ & $1,2,3$ & 384 & 384 \\
CSF1R & $94,59,72$ & $1,2,3$ & 730 & 730 \\
CYP1A1 & $95,57,72$ & $0.5,1.5,4$ & 700 & 600 \\
DCN1 & $94,57,72$ & $1,2,3$ & 1422 & 2000 \\
FES & $94,57,72$ & $0.5,1,1.5$ & 484 & 500 \\
GHR & $94,57,72$ & $1,2,3$ & 765 & 800 \\
GLB1 & $94,57,72$ & $1,2,3$ & 238 & 240 \\
PKLR & $94,59,72$ & $1,2,3$ & 600 & 630 \\
PVALB & $94,57,72(\mathrm{hs})$ & $0.5,1.5,4$ & 1400 & 1300 \\
RB1 & $94,59,72$ & $1,2,3$ & 695 & 1300 \\
\hline
\end{tabular}

${ }^{a}$ hs indicates "hot start" used.

within the range generally accepted (roughly 70 to $100 \%$ ) as demonstrating homology between the genes of mammalian species ( $\mathrm{Li}$ and Grauer, 1987). These results support the hypotheses that the canine PCR products are homologous to the respective index species' genes. The canine COL10Al sequence matched the human and mouse sequences to a similar extent (data not shown). The sequences for PKLR and CYPIA1 exactly matched previously published canine coding sequences (Whitney et al., 1994; Uchida et al., 1990); the sequence for canine FES is given in Fig. 3. Although the majority of the canine sequence for PVALB is from an intron, we believe that the degree of sequence identity from this region is sufficient evidence to confirm that the PCR product is from the correct canine locus. As expected, the canine sequences tend to show greater identity with the human sequences than with the rodent sequences because of the faster evolutionary rate of the rodent genome ( $\mathrm{Gu}$ and $\mathrm{Li}, 1993$ ). A microsatellite repeat was found within the amplified product itself for $R B 1$. Preliminary results show that the $R B 1$ repeat, $(\mathrm{GA})_{12(\mathrm{avg})}$, has moderate genetic variability within several canine breeds.

We hypothesized that each primer set should work for many mammals, given the evolutionary rate at which nucleotide substitutions occur ( $\mathrm{Li}$ and Grauer, 1987) and the number of primer nucleotide mismatches that can be tolerated by PCR. We tested the "universal" utility of these primers on the DNAs from mammals representing several different orders. We used the same reaction conditions that were found to amplify the canine sequences. We have termed these reactions "Zoo PCRs." Figure 4 shows a representative experiment. The $F E S$ protooncogene was amplified from all of the 


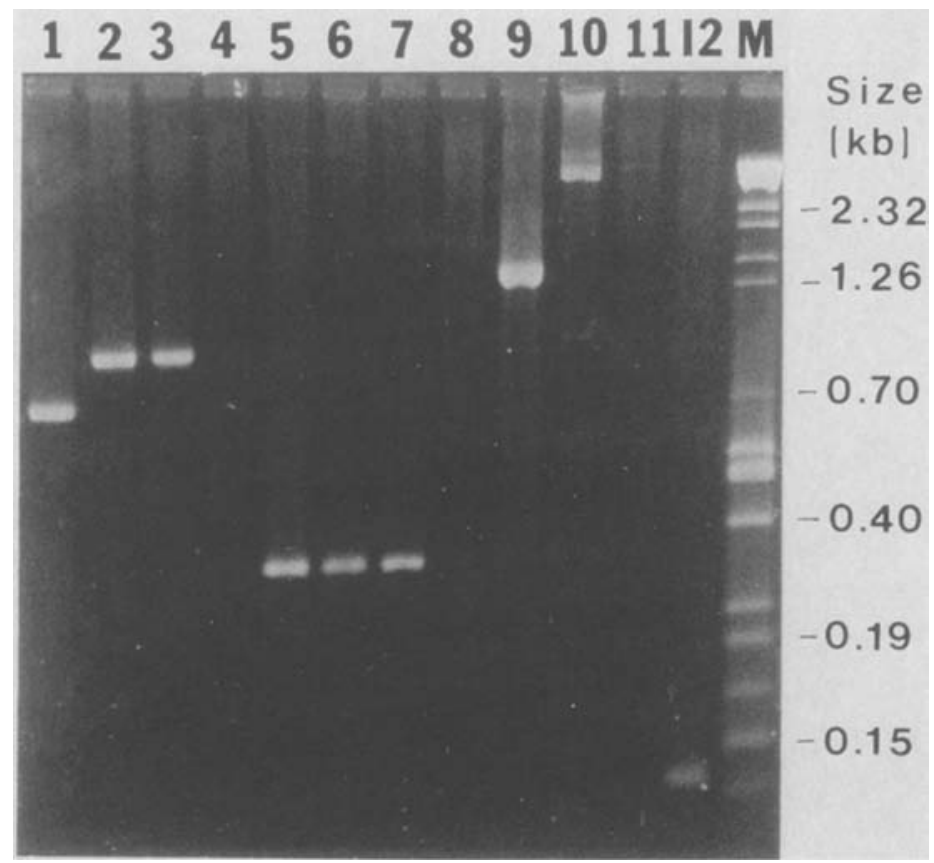

Fig. 1. Amplification of several canine gene segments using UM-STSs. The following lanes were amplified with the gene-specific primer sets (see Table I): lanes 1-4, GHR; lanes 5-8,COL10A1; and lanes 9-12, DCN1. Lane 13 contains a mixture of DNA size markers; $\lambda$ bacteriophage DNA cut with the restriction endonuclease BstEII and the plasmid pSK- (Stratagene) cut with MspI. Lanes 1,5, and 9 contain PCR products amplified from human genomic DNA. Lanes 2, 6, and 10 contain PCR products amplified from canine genomic DNA. Lanes 3, 7, and 11 contain PCR products amplified from DNA purified from a canine genomic library contained in a $\lambda$ bacteriophage vector. Lanes 4,8 , and 12 contain PCR products amplified from a canine liver cDNA library.

DNAs examined. These PCR products were purified and sequenced directly without subcloning (see Methods and Materials). The sequences are tabulated in Fig. 3. The degree of sequence identity makes it highly likely that the canine PCR products are all homologous to the corresponding index species' genes. The pattern of nucleotide interchange is also what would be expected for homologous genes; members of the same mammalian order share more sequence similarity with one another than with those of other orders.

The data for the Zoo PCRs for the other UM-STS primer sets reported in this paper are given in Table III. More than $84 \%$ of the targets, excluding the index and canine species, amplified under the single condition used to 
amplify the canine sequence. These species represent five mammalian orders: primates (human and macaque), carnivores (dog), artiodactyls (goat and pig), perissodactyls (horse), and rodents (mouse and rat). Limited experiments on other members of these orders (e.g., cat and ox) produced similar results (data not shown). Lack of amplification for DCN1 for one of the artiodactyls (goat) would be predicted because there are four mismatches between the UM-STS primers and the sequence of the closely related bovine DCN1 (Day et al., 1987). We have found it difficult (although not impossible) to amplify DNA using primers that contain more than two mismatches with the target when using 20 -mers (P.V., unpublished results). It is likely that the homologous gene from at least some of the nonamplifying species would appear using these primer sets if other PCR conditions were examined.

\section{DISCUSSION}

This study has shown the feasibility of generating a series of UM-STSs, useful for studies of many genomes, and addressed methodological considerations for their development. UM-STSs should serve as useful tools both for amplifying regions of interest from genomes and for isolation of clones from genomic and cDNA libraries and cross-species comparisons. The data reported in this paper indicate that approximately $85 \%$ of all carefully designed UM-STSs will be useful for any given mammalian species. We believe that this method is far more efficient, less costly, and considerably less labor intensive than traditional hybridization and Southern blottingbased methods. An additional important benefit is that the information for the necessary reagents (i.e., the primer sequences) is transmitted much more easily and quickly than the clones that are necessary for Southern blotting.

UM-STSs will also be useful for developing genetic markers within various genomes. We have found a microsatellite within 1 of the 11 loci reported here $(R B 1)$ and have found other microsatellite repeats associated with genomic clones isolated through the use of UM-STSs (unpublished results). Single-site variability should also be found directly in at least some of the amplified products by using one of a number of techniques developed for scanning for variability, such as the single-strand conformation polymorphism technique. For example, this method has been used to find two polymorphic sites in a study of the canine $A L A S 2$ gene in a PCR product of a size similar to those reported here (Boyer et al., 1995). If the frequency of single site polymorphic variability for other mammals is as high as that estimated for humans (roughly 1 in 200-400 nucleotides), then a significant portion of UM-STSs will have these sites. We are currently screening for this 

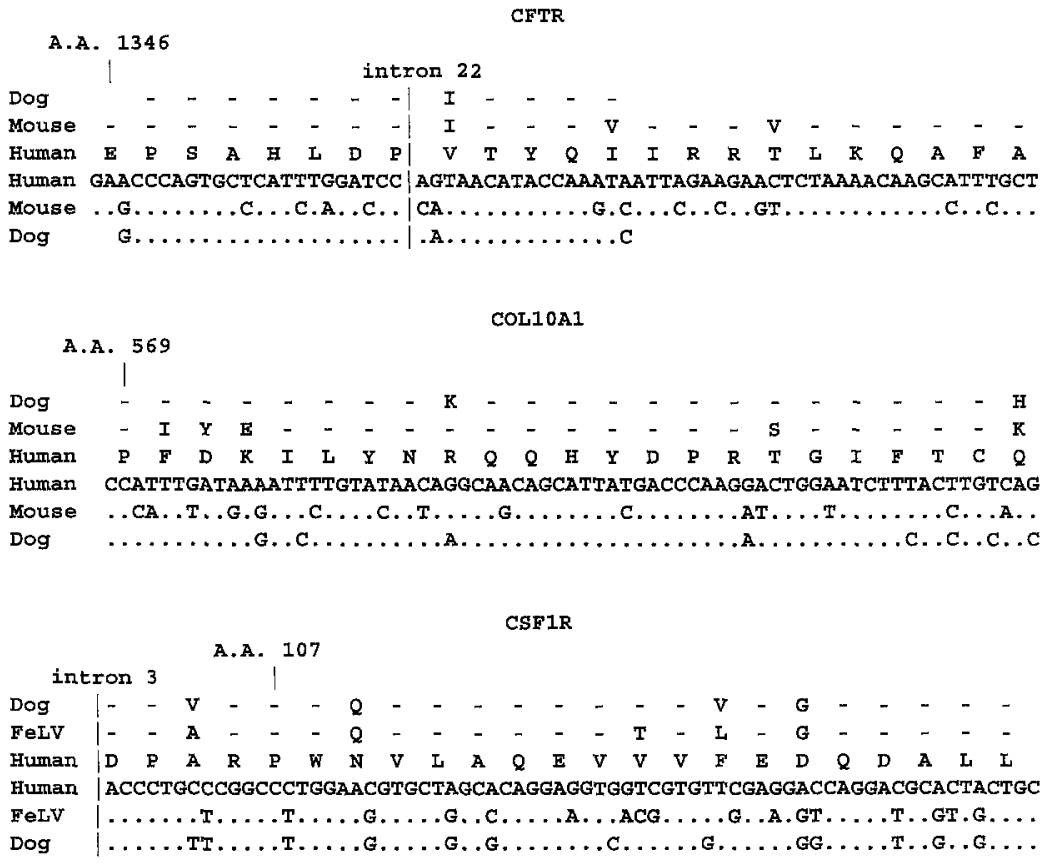

DCN1

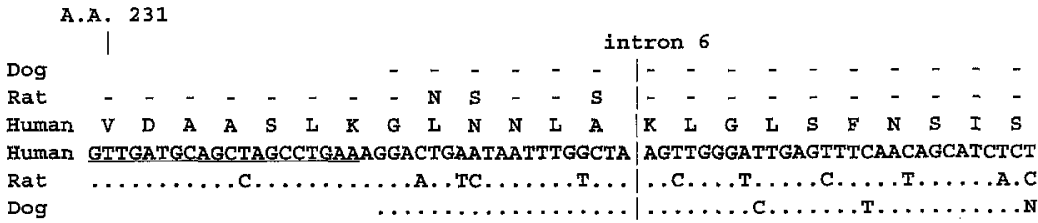

A.A. 333

GHR

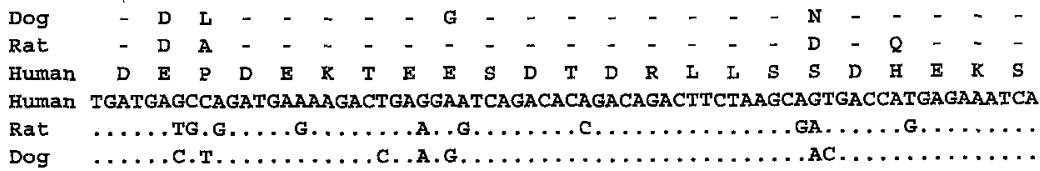

Fig. 2. Lineups of several canine gene sequences with homologous mammalian genes. The nucleotide and amino acid sequences are compared for each of several anchor loci between dog and two other species. The locations of PCR primers are underlined, although not all PCR primer sites are shown. Some of the lineups show intron sequence, whereas others simply identify the location of the introns. Genbank accession numbers for the canine sequences are as follows: CFTR, L77683 and L77689; COL10A1, L77672; CSFIR, L77670; DCN1, L77684; GHR, L77673; GLB1, L77671; PVALB, L77685 and L77686; and RB1, L77669. 

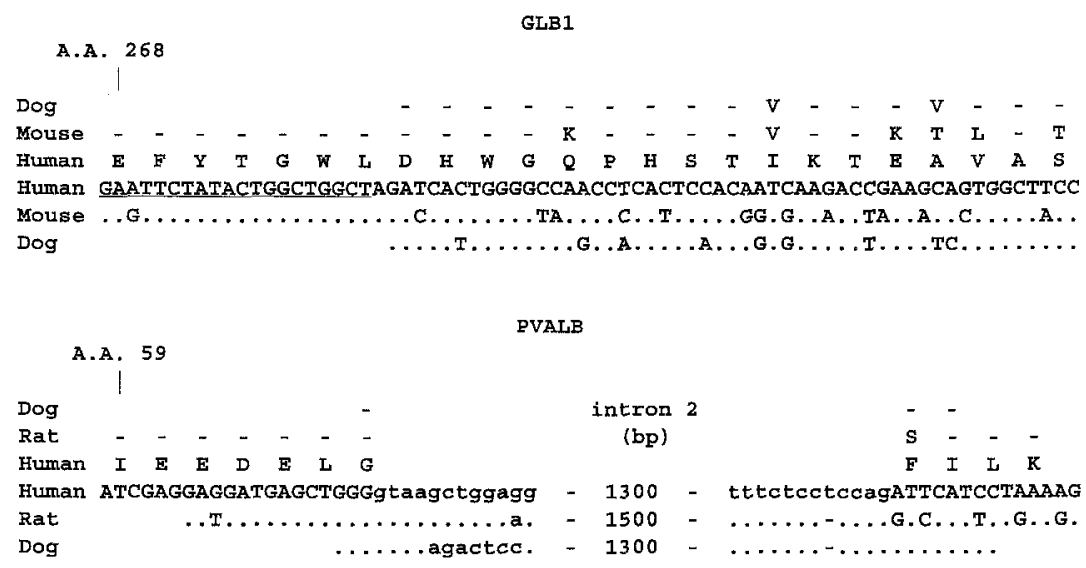

RB1

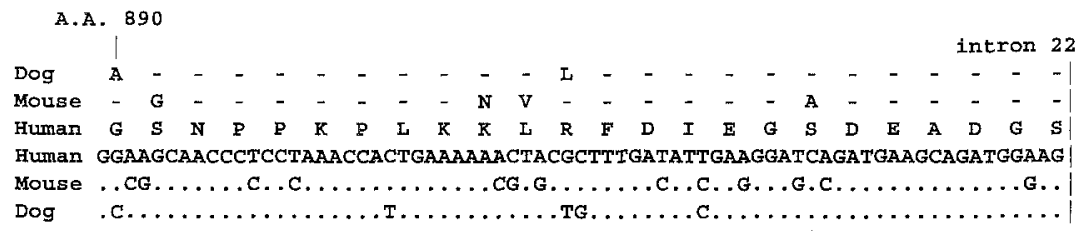

Fig. 2. (continued)

variability in the canine genome to estimate the frequency of such variation in the dog. It will be necessary to screen each species individually for genetic variability. However, the availability of previously designed UM-STS primer sets, such as those reported here, should make this work proceed more rapidly compared to the traditional method.

An example of the utility of cross-species comparisons is given by the case of Waardenburg syndrome. The clue to the location of one of the human Waardenburg syndrome genes-well-known for causing a syndromic hearing loss-was first gleaned from comparative mapping with the mouse (Asher and Friedman, 1990). The map locations in the mouse suggested possible locations of the human disease gene, one of which eventually was proven correct (e.g., Morell et al., 1992). Because the identity of the gene in the mouse was not known at the time, this approach might more properly be called a "positional candidate" approach. UM-STSs will be useful for rapidly producing mammalian genetic maps so that the positional candidate approach can be applied to more species.

Very little is known about the location of genes within the canine genome. Indeed, except for genes located on the X chromosome (MeeraKhan, 1984; Deschenes et al., 1994) and a few small unassigned linkage 

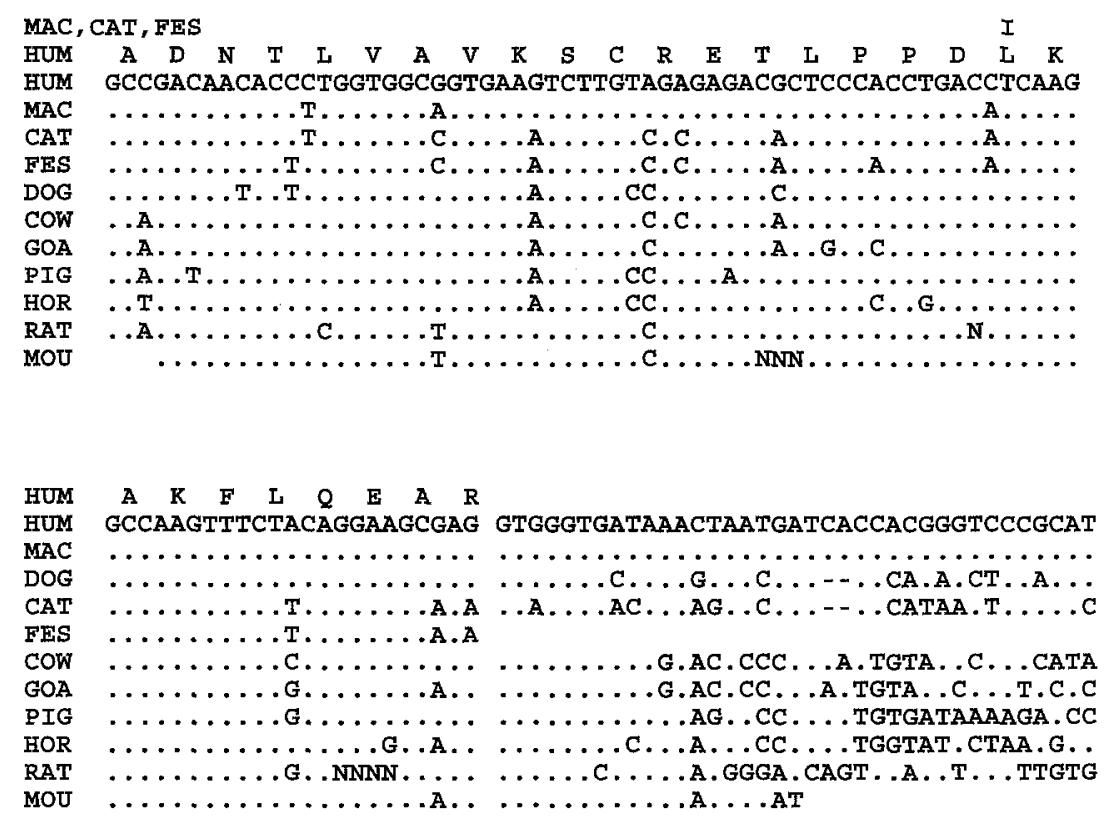

Fig. 3. Sequence of a portion of the $F E S$ protooncogene from several mammalian DNAs. Sequences are from exon 15 and intron 15. Notations for the sequence lineups are as follows: HUM, human; MAC, macaque; CAT, domestic cat; FES, feline sarcoma virus; DOG, dog; COW, ox; GOA, goat; HOR, horse; PIG, pig; RAT, rat; and MOU, mouse. The upper two lines for each block of text represent amino acid sequences and the lower lines represent nucleotide sequences. Dots indicate nucleotides in the various species that are identical to those of the human sequence. The human and cat sequences determined here exactly match the published sequences (Alcalay et al., 1990; Roebroek et al., 1987). The feline sarcoma virus sequence was not determined in this study but is included for comparative purposes. Only a single amino acid interchange was found among these sequences; isoleucine (I) for macaque, cat, and feline sarcoma virus and leucine (L) in all others. Sequence alignments for the intron were done visually and may not be optimal. Genbank accession numbers for these sequences are as follows: MACFES, L77678; DOGFES, L77674; CATFES, L77675; COWFES, L77677; GOAFES, L77681; PIGFES, L77679; HORFES, L77676; RATFES, L77680; and MOUFES, L77682.

groups (Meera-Khan, 1984), their locations (Holmes et al., 1992; Ostrander et al., 1993; Rothuizen et al., 1994; Yuzbasiyan-Gurkan et al., 1993) are based primarily on simple sequence repeats. The development of UM-STSs should help to identify rapidly the location of linkage groups on specific canine chromosomes. The identification of conserved syntenies will allow candidate linkages to be tested in the canine genome. The assignment of the proposed anchor loci (O'Brien et al, 1993) as defined by UM-STSs to specific chromosomes can be accomplished by the somatic cell hybrid, flow sorted chromosome, and fluorescent in situ hybridization (FISH) methodologies. Other methods, such as assignment by use of linkage to previously mapped 


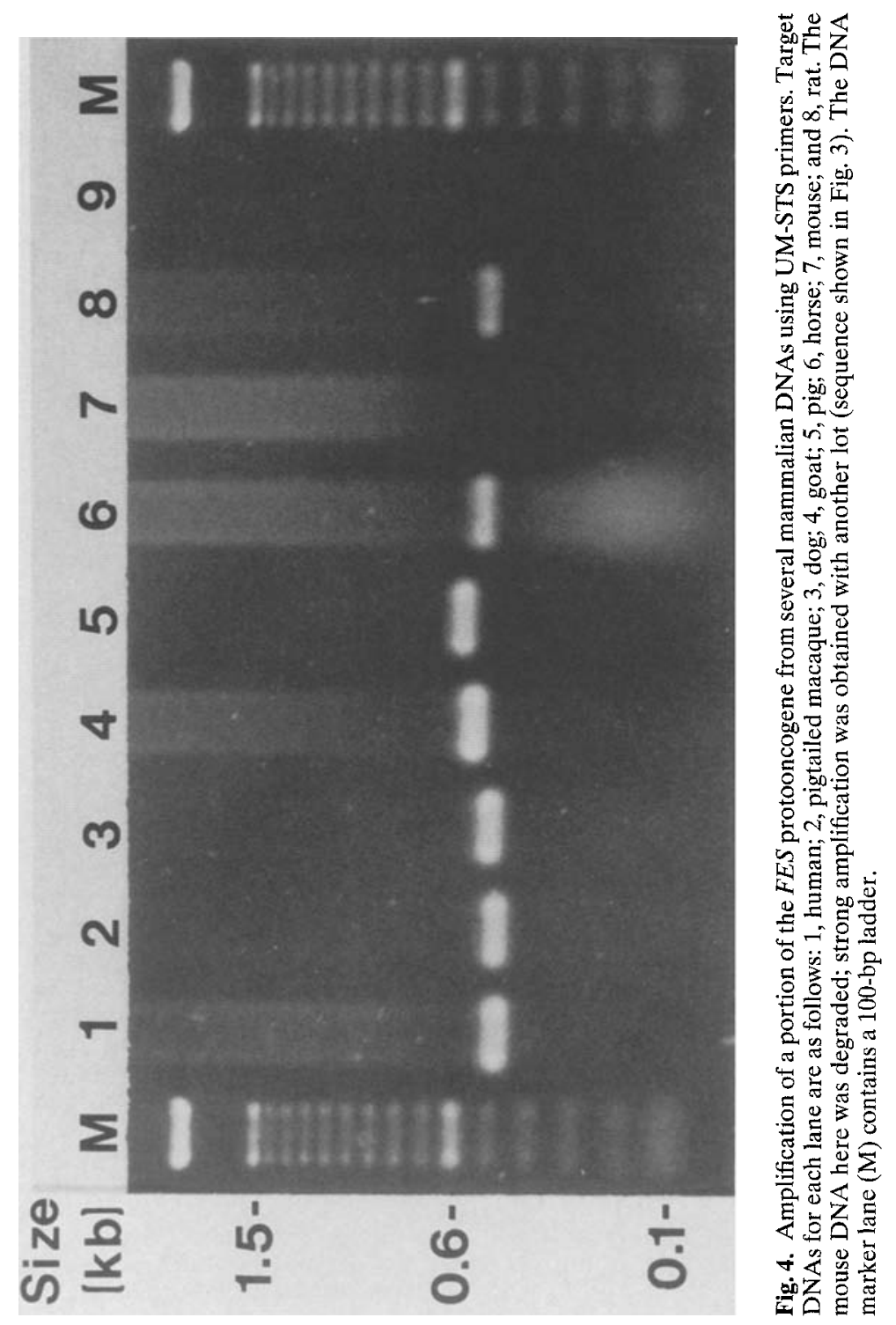


Table III. Summary of Amplification Results for UM-STSs for Several Mammalian DNAs ${ }^{a}$

\begin{tabular}{lcccccccc}
\hline Locus & Human & Macaque & Dog & Goat & Pig & Horse & Mouse & Rat \\
\hline CFTR & $+b$ & + & + & - & + & + & + & + \\
COL10A1 & + & + & + & - & + & + & + & + \\
CSF1R & + & + & + & + & - & - & + & + \\
CYP1A1 & + & + & + & + & + & + & + & + \\
DCNI & + & + & + & - & + & + & + & + \\
FES & + & + & + & + & + & + & + & + \\
GHR & + & + & + & + & + & + & + & + \\
GLB1 & + & + & + & + & + & + & + & + \\
PKLR & + & + & + & + & + & - & + & + \\
$P V A L B$ & + & + & + & + & + & + & + & + \\
RB1 & + & + & + & - & + & + & + & + \\
\hline
\end{tabular}

${ }^{a}+$, Amplification; - , no amplification.

${ }^{b}$ Boldface symbols indicate index species.

loci, are also possible. We have already assigned several genes by FISH to canine chromosomes using cosmids isolated with UM-STSs (Fujita et al., 1996). Using the methods described here, we have developed a much greater number of UM-STSs that should cover, for linkage mapping purposes, a substantial portion of the canine and other mammalian genomes (see Appendixes 1 and 2).

\section{APPENDIX 1}

Table AI. Eighty-Six ${ }^{a}$ Universal Mammalian Sequence-Tagged Sites-Human Chromosomal Locations and Names

\begin{tabular}{|c|c|c|c|c|}
\hline $\begin{array}{l}\text { Locus } \\
\text { name }\end{array}$ & Gene product & $\begin{array}{l}\text { Human } \\
\text { chromosome }\end{array}$ & $\begin{array}{l}\text { Primer } 1 \\
\text { name }\end{array}$ & $\begin{array}{l}\text { Primer } 2 \\
\text { name }\end{array}$ \\
\hline$P N D$ & Pronatriodilatin & $1 \mathrm{p} 36$ & DPNDEX1D & DPNDEX2U \\
\hline$P K L R$ & Pyruvate kinase- $-\mathrm{RBC}$ & $1 \mathrm{q} 21$ & HPKLREX4D & HPKLREX6U \\
\hline AT3 & Antithrombin III & $1 \mathrm{q} 23-\mathrm{q} 25$ & HAT3EX3D & HAT3EX4U \\
\hline$R E N$ & Renin & $1 \mathrm{q} 32$ & HRENEX8D & HRENEX9U \\
\hline SFTP3 & $\begin{array}{l}\text { Pulmonary surfactant } \\
\text { protein } 3\end{array}$ & $2 \mathrm{p} 11.2$ & DSFTP3EX4D & DSFTP3EX5U \\
\hline SPTBN1 & $\beta$-Spectrin (non-RBC) & $2 \mathrm{p} 21$ & HSPTBN1EX13D & HSPTBN1EX14U \\
\hline$A P O B$ & Apolipoprotein B & $2 \mathrm{p} 24-\mathrm{p} 23$ & HAPOBEX26D & HAPOBEX $26 \mathrm{U}$ \\
\hline$I L I A$ & Interleukin $1 \alpha$ & $2 \mathrm{q} 13$ & HIL1AEX2D & SIL1AEX3U \\
\hline COL $3 A 1$ & Collagen III $\alpha_{1}$ & $2 q 31-q 32.3$ & HCOL3A1EX24D & HCOL3A1EX25U \\
\hline$E L N$ & Elastin & 2 q31-qter & HELNEX32D & HELNEX33U \\
\hline$P A X 3$ & Human paired domain 2 & $2 q 34-q 36$ & HHUP2EX2D & HHUP2EX3U \\
\hline$G C G$ & Glucagon & $2 q 36-q 37$ & HGCGEX4D & HGCGEX5U \\
\hline PIT1 & $\begin{array}{l}\text { Pituitary-specific tran- } \\
\text { scription factor } 1\end{array}$ & 3 p11 & HPIT1EX4D & HPIT1EXSU \\
\hline
\end{tabular}


Table AI. (continued)

\begin{tabular}{|c|c|c|c|c|}
\hline $\begin{array}{l}\text { Locus } \\
\text { name }\end{array}$ & Gene product & $\begin{array}{c}\text { Human } \\
\text { chromosome }\end{array}$ & $\begin{array}{c}\text { Primer } 1 \\
\text { name }\end{array}$ & $\begin{array}{c}\text { Primer } 2 \\
\text { name }\end{array}$ \\
\hline GLB1 & $\beta$-galactosidase & 3 pter-p21 & HGLB1EX8D & HGLB1EX9U \\
\hline$G P X 1$ & Glutathione peroxidase 1 & $3 q 11-q 12$ & HGPX1EX1D & HGPX1EX2U \\
\hline$T F$ & Transferrin & $3 \mathrm{q} 21$ & HTFEX7D & HTFEX8U \\
\hline RHOI & Rhodopsin & 3 q21-qter & HRHOEX3D & HRHOEX4U \\
\hline GLUT2 & Glucose transport-like 2 & 3 q26.1-q26.3 & HGLUT2EX9D & HGLUT2EX10U \\
\hline SST & Somatostatin & $3 \mathrm{q} 28$ & HSSTEX1D & HSSTEX2U \\
\hline HOX7 & Homeobox 7 & 4 p16.1 & HHOX7EX2D & HHOX7EX2U \\
\hline$P D E B$ & cGMP phosphodiesterase $\beta$ & 4 pter & HPDEBEX14D & HPDEBEX15U \\
\hline$A L B$ & Albumin & $4 q 11-q 13$ & HALBEX4D & HALBEX5U \\
\hline KIT & c-KIT protooncogene & $4 \mathrm{q} 12-\mathrm{q} 13$ & HKITEX18D & HKITEX20U \\
\hline$F G G$ & Fibrinogen $\gamma$ & $4 \mathrm{q} 28$ & HFGGEX8D & HFGGEX9U \\
\hline GHR & $\begin{array}{l}\text { Growth hormone } \\
\text { receptor }\end{array}$ & $5 \mathrm{p} 13.1-\mathrm{p} 12$ & HGHREX9D & HGHREXI0U \\
\hline$H E X B$ & $\beta$-Hexosaminidase & $5 \mathrm{q} 13$ & HHEXBEX12D & HHEXBEX13U \\
\hline IL4 & Interleukin 4 & $5 q 23-q 31$ & HIL4EX1D & HIL4EX2U \\
\hline$A D R B 2$ & Adrenergic receptor $\beta_{2}$ & $5 q 31-q 32$ & HADRB2EX1D & HADRB2EX1U \\
\hline$C S F 1 R$ & CSF-1 receptor & $5 q 33-q 35$ & HCSF1REX3D & HCSF1EX4U \\
\hline TNFA & Tumor necrosis factor $\alpha$ & $6 \mathrm{p} 21.3$ & HTNFAEX1D & HTNFAEX4U \\
\hline EDN1 & Endothelin 1 & $6 \mathrm{p} 24-\mathrm{p} 23$ & HEDN1EX3D & HEDN1EX4U \\
\hline $\operatorname{COL} 9 A 1$ & Collagen IX $\alpha$ I & $6 \mathrm{q} 12-\mathrm{q} 14$ & HCOL9A1EX3D & HCOL9A1EX4U \\
\hline COL10A1 & Collagen Type X $\alpha \mathrm{I}$ & $6 \mathrm{q} 21-\mathrm{q} 22$ & HCOL10A1EX2D & HCOL10A1EX2U \\
\hline$P L G$ & Plasminogen & $6 \mathrm{q} 25-\mathrm{q} 27$ & HPLGEX18D & HPLGEX19U \\
\hline$E P O$ & Erythropoeitin & 7 q21 & HEPOEX2D & HEPOEX3U \\
\hline CFTR & Cystic fibrosis trans. regu- & & & \\
\hline$C R B$ & $\begin{array}{l}\text { lator } \\
\text { T-cell receptor } \beta\end{array}$ & $7 \mathrm{q} 35$ & $\begin{array}{l}\text { HCFTREX22D } \\
\text { DTCRBEX2D }\end{array}$ & $\begin{array}{l}\text { HCFTREX23U } \\
\text { DTCRBEX3U }\end{array}$ \\
\hline SFTP2 & Pulmonary suractant pro- & & & \\
\hline & & $8 \mathrm{p} 21$ & HSFTP & HSFTP2 \\
\hline$C A 2$ & Carbonic anhydrase II & $8 \mathrm{q} 22$ & CAUNIVEX3D & HCAIIEX4U \\
\hline$T G$ & Thyroglobulin & $8 \mathrm{q} 24$ & HTGEX9D & HTGEX10U \\
\hline$A L D O B$ & Aldolase B & $9 \mathrm{q} 21.3-\mathrm{q} 22.2$ & HALDOBEX7D & HALDOBEX8U \\
\hline$C 5$ & Complement factor 5 & $9 \mathrm{q} 22-\mathrm{q} 34$ & HC5EX36D & HC5EX37U \\
\hline$A B L$ & ABL protooncogene & 9 q34 & HABLEX10D & HABLEX11U \\
\hline$R E T$ & RET protooncogene & $10 \mathrm{q} 11.2$ & HRETEX19D & HRETEX20U \\
\hline$T D T$ & Terminal transferase & $10 \mathrm{q} 23-\mathrm{q} 24$ & HTDTEX9D & HTDTEX10U \\
\hline$O A T$ & Ornithine aminotrans- & & & \\
\hline & & $10 \mathrm{q} 26$ & HOATH & HOATEX8U \\
\hline$W T 1$ & Wilms tumor 1 & $11 \mathrm{p} 13$ & HWT1EX8D & HWT1EX9U \\
\hline$L D H A$ & Lactate dehydrogenase A & $11 \mathrm{p} 14-15.5$ & HLDHAEX3D & HLDHAEX4U \\
\hline INS & Insulin & $11 \mathrm{p} 15.5$ & DINSEX2D & DINSEX $3 \mathrm{U}$ \\
\hline$C D 20$ & $\mathrm{CD} 20$ & $11 \mathrm{q} 12-\mathrm{q} 13.1$ & HCD20EX6D & HCD 20EX7U \\
\hline ROMI & $\begin{array}{l}\text { Rod outer segment pro- } \\
\text { tein-1 }\end{array}$ & & & \\
\hline$A P O C 3$ & Apolipoprotein $\mathrm{C} 3$ & 11 q23-qter & DAPOC $3 E X 2 D$ & DAPOC $3 E X 3 U$ \\
\hline$V W F$ & von Willebrand's factor & $12 \mathrm{p}$ & HVWFEX46D & HVWFEX $47 \mathrm{U}$ \\
\hline$L D H B$ & Lactate dehydrogenase B & $12 \mathrm{p} 12.1-12.2$ & HLDHBEX3D & HLDHBEX4U \\
\hline IL6 & Interleukin 6 & $12 \mathrm{p} 12.2-\mathrm{p} 12$ & HIL6EX3D & DIL6EX4U \\
\hline$T P I$ & Triosphosphate isom- & & & \\
\hline
\end{tabular}


Table AI. (continued)

\begin{tabular}{|c|c|c|c|c|}
\hline $\begin{array}{l}\text { Locus } \\
\text { name }\end{array}$ & Gene product & $\begin{array}{l}\text { Human } \\
\text { chromosome }\end{array}$ & $\begin{array}{l}\text { Primer } 1 \\
\text { name }\end{array}$ & $\begin{array}{c}\text { Primer } 2 \\
\text { name }\end{array}$ \\
\hline COL2AI & Collagen II $\alpha 1$ & $12 \mathrm{q} 14.3$ & HCOL2A1EX2D & HCOL2A1EX3U \\
\hline$D C N 1$ & Decorin & $12 q 21-q 23$ & HDCNEX6D & HDCNEX7U \\
\hline$I G F I$ & Insulin-like growth factor 1 & $12 q 22$ & HIGF1EX3D & HIGF1EX4U \\
\hline$P L A 2$ & Phospholipase A2 & 12 q23-qter & DPLA2EX2D & DPLA2EX3U \\
\hline$R B 1$ & Retinoblastoma 1 & 13 q14.2 & HRB1EX25D & HRB1EX26U \\
\hline$F 7$ & Clotting factor VII & $13 \mathrm{q} 34$ & HF7EX7D & HF7EX8U \\
\hline$C H Y$ & Chymase (mast cell) & 14 q11.2 & DCHYEX4D & DCHYEX5U \\
\hline$C K B B$ & Creatine kinase brain & $14 \mathrm{q} 32.3$ & DCKBEX6D & DCKBEX8U \\
\hline TCRA & T-cell receptor $\alpha$ & $14 \mathrm{q} 34$ & DTCRAEX3D & DTCRAEX4U \\
\hline$B 2 M$ & $\beta$-2-Microglobulin & $15 \mathrm{q} 21-\mathrm{q} 22.2$ & HB2MEX2D & HB2MEX3U \\
\hline$C Y P 1 A I$ & $\begin{array}{l}\text { Cytochrome P-450 } \\
\text { (AHH) }\end{array}$ & $15 \mathrm{q} 22-\mathrm{q} 24$ & DCYP1A1EX3D & DCYP1A1EX5U \\
\hline$P K M$ & Pyruvate kinase--muscle & 15 q22-qter & HPKMEX2D & HPKMEX3U \\
\hline FES & FES protooncogene & 15 q25-qter & HFESEX14D & HFESEX15U \\
\hline $\begin{array}{l}H G B A \\
G O T 2\end{array}$ & $\alpha$-Hemoglobin & 16 p13.3 & HHGBAEX2D & HHGBAEX3U \\
\hline GOT2 & $\begin{array}{l}\text { Glutamate oxaloacetate } \\
\text { transaminase } 2\end{array}$ & $16 \mathrm{q} 21-\mathrm{q} 22$ & HGOT2EX5D & HGOT2EX7U \\
\hline$C T R B$ & Chymotrypsinogen & $16 \mathrm{q} 22.3-\mathrm{q} 23.2$ & DCTRBEX5D & DCTRBEX6U \\
\hline$A P R T$ & $\begin{array}{l}\text { Adenosine PR trans- } \\
\text { ferase }\end{array}$ & 16 q24 & HAPRTEX3D & HAPRTEX5U \\
\hline TP53 & Tumor protein 53 & $17 \mathrm{p} 13.1$ & HTP53EX5D & HTP53EX7U \\
\hline NF1 & Neurofibromatosis 1 & $17 \mathrm{q} 11.2$ & HNF1EX6D & HNF1EX7U \\
\hline$S C N 4 A$ & $\begin{array}{l}\text { Skeletal muscle sodium } \\
\text { channel }\end{array}$ & $17 \mathrm{q} 23.1-\mathrm{q} 25.3$ & HSCN4AEX23D & HSCN4AEX24U \\
\hline$T S$ & Thymidylate synthetase & 18 pter-q12 & HTSEX5D & HTSEX6U \\
\hline$A P O C 2$ & Apolipoprotein C2 & $19 \mathrm{q} 13.2$ & DAPOC2EX3D & DAPOC2EX4U \\
\hline$C K M M$ & Creatine kinase muscle & 19 q13.2-q13.3 & DCKMEX2D & DCKMEX3U \\
\hline$P V A L B$ & Parvalbumin & 22 q12-q13.1 & HPVALBEX3D & HPVALBEX4U \\
\hline$D Y S$ & Dystrophin & $\mathrm{X}$ p 21 & DDYSEX7D & DDYSEX7U \\
\hline$M N K$ & Menkes protein & X q12-q13.3 & HMNKEX4 & HMNKEX4 \\
\hline$H P R T$ & $\begin{array}{l}\text { Hypoxanthine PR trans- } \\
\text { ferase }\end{array}$ & $\mathrm{Xq} 26$ & HHPRTEX7D & HHPRTEX8U \\
\hline$F 9$ & Clotting factor IX & $X q 26.3-q 27.1$ & DF9EX7D & DF9EX8U \\
\hline$F 8$ & Clotting factor VIII & $\mathrm{Xq} 28$ & HF8EX24D & HF8EX25U \\
\hline$S R Y$ & $\begin{array}{l}\text { Sex determining } \\
\text { region-Y }\end{array}$ & Y p11.3 & HSRYEX1D & HSRYEX1U \\
\hline
\end{tabular}

${ }^{a}$ For convenience, the 11 loci described in detail are included in the Appendixes. 


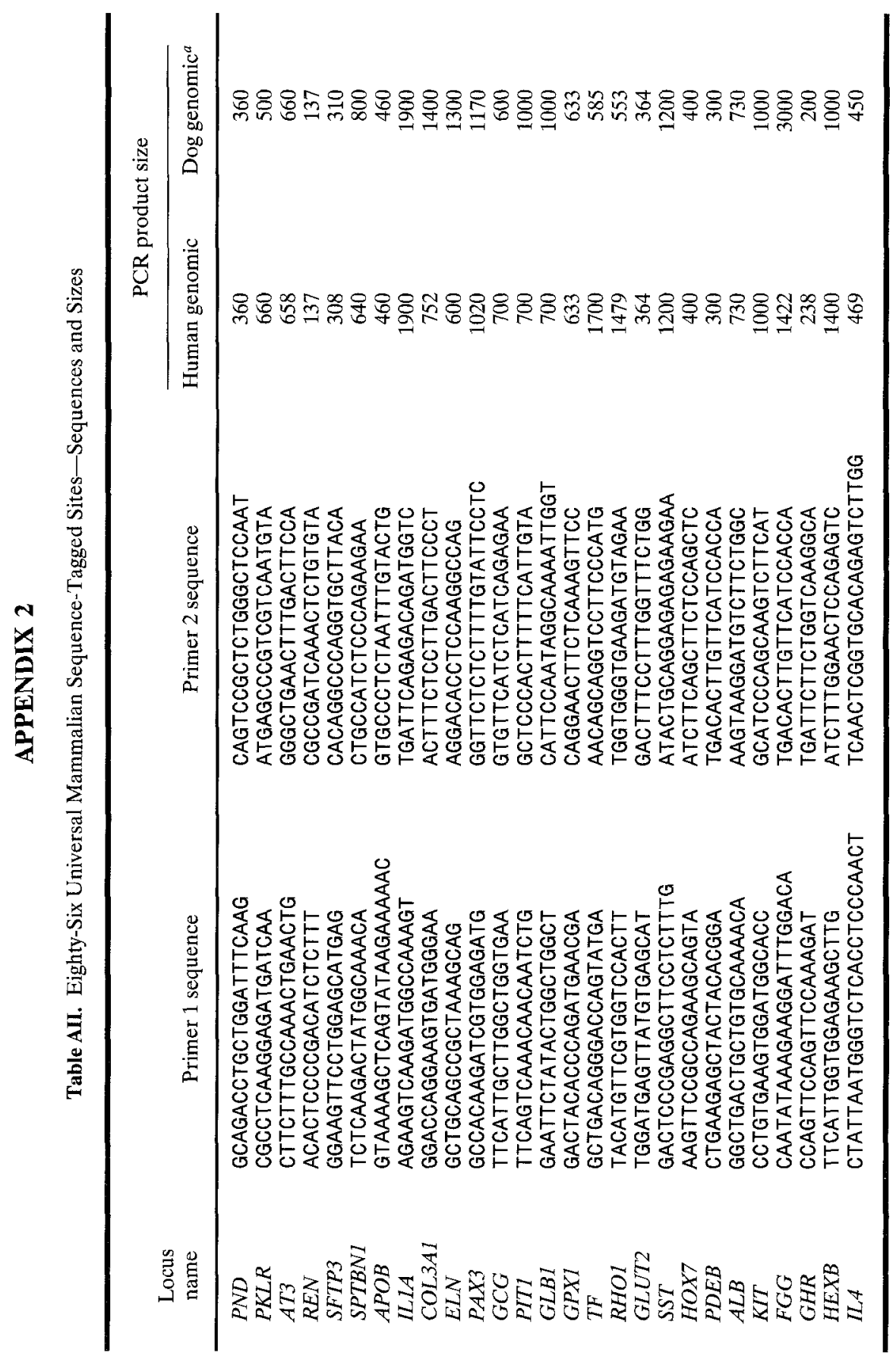




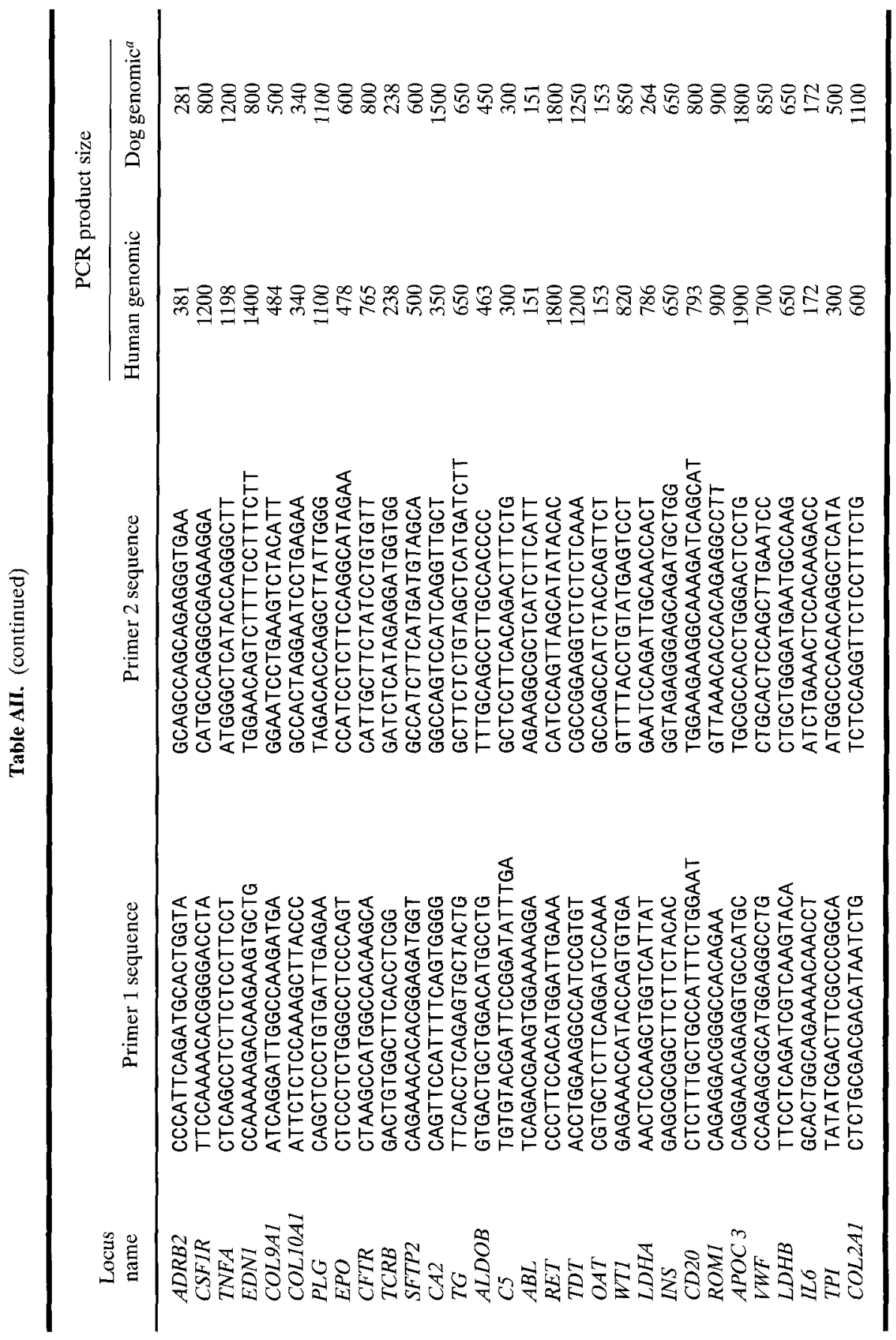




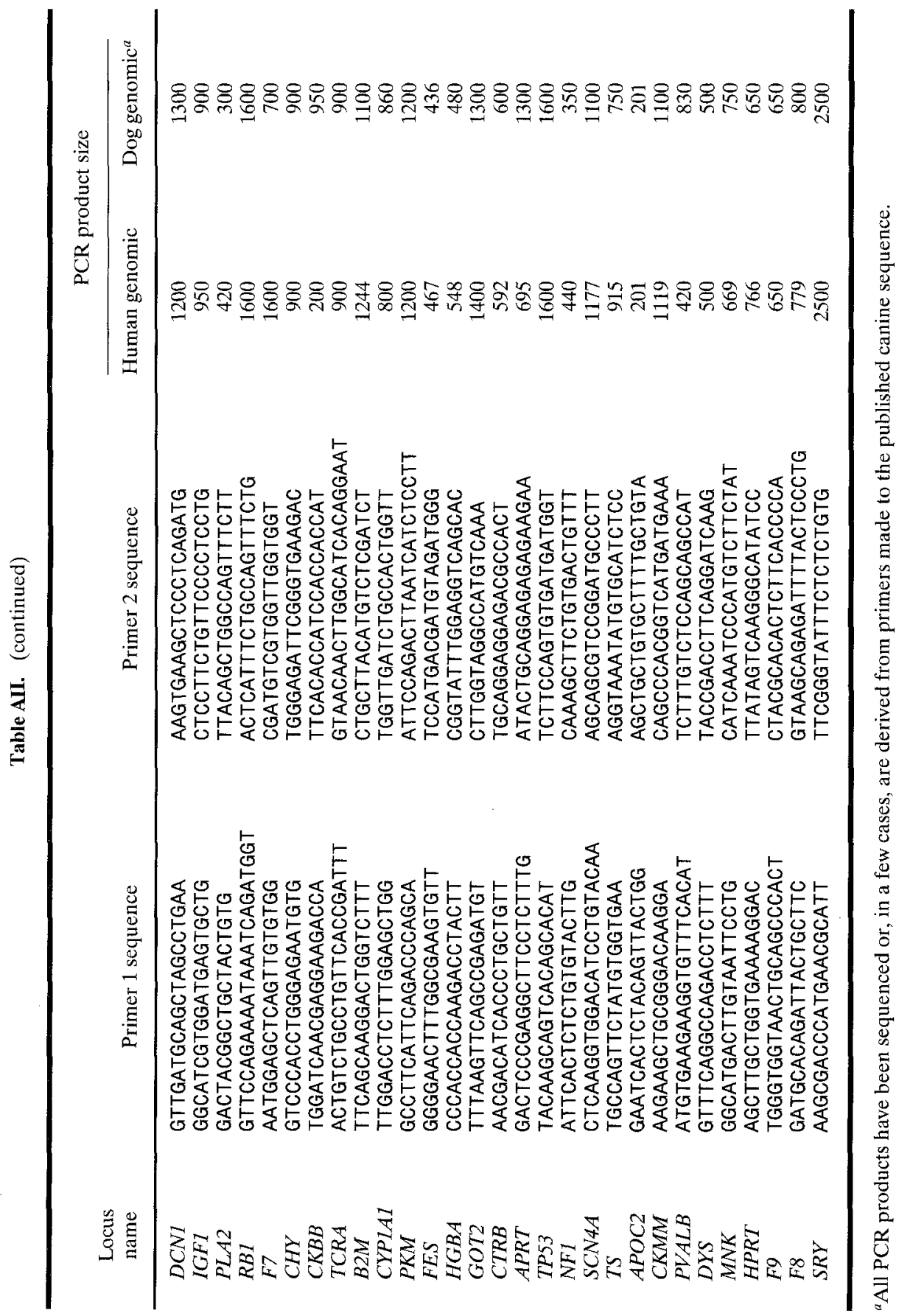




\section{ACKNOWLEDGMENTS}

We thank Ya Shiou Yu and Murat Gurkan for their valuable technical assistance. We also thank Tracy Hammer, Neal Dittmer, Jessica Nadler, Elizabeth Tullett, Marc Crotteau, and Kristen Penner for their contributions to the development of a number of the primer sets. This work was supported by the American Kennel Club, the Orthopedic Foundation for Animals, and the Morris Animal Foundation. We also thank the Washington Regional Primate Facility for supplying the pigtail macaque tissues to Dr. Richard E. Tashian, with whom one of us (P.V.) originally isolated the DNA.

\section{REFERENCES}

Alcalay, M., Antolini, F., Van de Ven, W. J., Lanfrancone, L., Grignani, F., and Pelicci, P. G. (1990). Characterization of human and mouse $c$-fes cDNA clones and identification of the 5 ' end of the gene. Oncogene 5:267.

Asher, J. H. J., and Friedman, T. B. (1990). Mouse and hamster mutants as models for Waardenburg syndromes in humans. J. Med. Genet. 27:618.

Barendse, W., Armitage, S. M., Kossarek, L. M., Shalom, A., Kirkpatrick, B. W., Ryan, A. M., Clayton, D., Li, L., Neibergs, H. L., Zhang, N., Grosse, W. M., Weiss, J., Creighton, P., McCarthy, F., Ron, M., Teale, A. J., Fries, R., McGraw, R. A., Moore, S. S., Georges, M., Soller, M., Womack, J. E., and Hetzel, D. J. S. (1994). A genetic linkage map of the bovine genome. Nat. Genet. 6:227.

Bassam, B. J., and Caetano-Anolles, G. (1993). Automated "hot start" PCR using mineral oil and paraffin wax. Biotechniques 14:30.

Bergenhem, N. C. H., Venta, P. J., Hopkins, P. J., and Tashian, R. E. (1992). Variation in coding exons of two electrophoretic alleles at the pigtail macaque carbonic anhydrase I locus as determined by direct, double-stranded sequencing of polymerase chain reaction (PCR) products. Biochem. Genet. 30:279.

Boyer, G., Nonneman, D., Shibuya, H., Stoy, S. J., O'Brien, D., and Johnson, G. S. (1995). A PCR-RFLP marker for the erythroid aminolevulinate synthase gene (ALSA2) on canine chromosome X. Anim. Genet. 26:206.

Breslauer, K., Frank, R., Blocker, H., and Markey, L. A. (1986). Predicting DNA duplex stability from the base sequence. Proc. Natl. Acad. Sci. USA 83:3746.

Buchanan, F. C., Adams, L. J., Littlejohn, R. P., Maddox, J. F., and Crawford, A. M. (1994). Determination of evolutionary relationships among sheep breeds using microsatellites. Genomics 22:397.

Collins, D. W., and Jukes, T. H. (1994). Rates of transition and transversion in coding sequences since the human-rodent divergence. Genomics 20:386.

Day, A. A., McQuillan, C. I., Termine, J. D., and Young, M. R. (1987). Molecular cloning and sequence analysis of the cDNA for small proteoglycan II of bovine bone. Biochem. J. 248:801.

Deschenes, S. M., Puck, J. M., Dutras, A. S., Somberg, R. L., Felsburg, P. J., and Henthorn, P. S. (1994). Comparative mapping of canine and human proximal $\mathrm{Xq}$ and genetic analysis of canine X-linked severe combined immunodeficiency. Genomics 23:62.

Dietrich, W., Katz, H., Lincoln, S. E., Shin, H.-P., Friedman, J., Dracopoli, N. C., and Lander, E. S. (1992). A genetic map of the mouse suitable for typing intraspecific crosses. Genetics 131:423.

Ellegren, H., Johansson, M., Sandberg, K., and Andersson, L. (1992). Cloning of highly polymorphic microsatellites in the horse. Anim. Genet. 23:133.

Fujita, M., Loechel, R., McFarlin, K., Brewer, G. J., Venta, P., and Yuzbasiyan-Gurkan, V. 
(1996). Assignment and localization of a set of genes to canine chromosomes using fluorescent in situ hybridization. Mammal. Genome 7:268.

$\mathrm{Gu}, \mathrm{X}$., and Li, W.-H. (1993). Higher rates of amino acid substitution in rodents than in humans. Mol. Phylogen. Evol. 1:211.

Holmes, N. G., Mellersh, C. S., Humphreys, S. J., Holliman, A., Curtis, R., and Sampson, J. (1992). Isolation and characterization of microsatellites from the canine genome. Anim. Genet. 24:289.

ISGN (1987). Guidelines for human gene nomenclature: An international system for human gene nomenclature (ISGN, 1987). Cytogenet. Cell Genet. 46:11.

Li, W.-H., and Grauer, D. (1987). Fundamentals of Molecular Evolution, Sinauer Associates, Sunderland, MA.

Meera Khan, P., Brahe, C., and Wijnen, L. M. M. (1984). Gene map of the dog: Six conserved and three disrupted syntenies. Cytogenet. Cell Genet. 37:537.

Morell, R., Friedman, T. B., Moeljopawiro, S., Hartono, Soewito, and Asher, J. H., Jr. (1992). A frameshift mutation in the HuP2 paired domain of the probable human homolog of murine Pax-3 is responsible for Waardenburg syndrome type 1 in an Indonesian family. Hum. Mol. Genet. 1:243.

Murray, N. E., Brammer, W. J., and Murray, K. (1977). Lambdoid phages that simplify the recovery of in vitro recombinants. Mol. Gen. Genet. 156:53.

O'Brien, S. J. (1986). Molecular genetics in the domestic cat and its relatives. Trends Genet. 2:137.

O'Brien, S. J., Womack, J. E., Lyons, L. A., Moore, K. J., Jenkins, N. A., and Copeland, N. G. (1993). Anchored reference loci for comparative genome mapping in mammals. Nat. Genet. 3:103.

Olsen, M., Hood, L., Cantor, C., and Botstein, D. (1989). A common language for physical mapping of the human genome. Science 245:1434.

Ostrander, E. A., Sprague, G. F., and Rine, J. (1993). Identification and characterization of dinucleotide repeat $(C A)_{n}$ markers for genetic mapping in dog. Genomics 16:207.

Roebroek, A. J. M., Schalken, J. A., Onnekink, C., Bloemers, H. P. J., and Van de Ven, W. J. (1987). Structure of the feline c-fes/fps proto-oncogene: Genesis of a retroviral oncogene. J. Virol. 61:2009.

Rothuizen, J., Wolfswinkel, J., Lenstra, J. A., and Frants, R. R. (1994). The incidence of miniand micro-satellite repetitive DNA in the canine genome. Theor. Appl. Genet. 89:403.

Sambrook, J., Fritsch, E. F., and Maniatis, T. (1989). Molecular Cloning. A Laboratory Manual (2nd ed.), Cold Springs Harbor Laboratory Press, Cold Springs Harbor, NY.

Serikawa, T., Kuramoto, T., Hilbert, P., Mori, M., Yamada, J., Dubay, C. J., Lindpainter, K., Ganten, D., Guenet, J.-L., Lathrop, G. M., and Beckmann, J. S. (1992). Rat gene mapping using PCR-analyzed microsatellites. Genetics 131:701.

Uchida, T., Komori, M., Kitada, K., and Kamataki, T. (1990). Isolation of cDNAs coding for three different forms of liver microsomal cytochrome P-450 form polychlorinated biphenyltreated beagle dogs. Mol. Pharmacol. 38:644.

Weissbach, J., Gyapay, G.; Dib, C., Vignal, A., Morissette, J., Millasseau, P., Vaysseix, G., and Lathrop, M. (1992). A second-generation linkage map of the human genome. Nature 359:794.

Whitney, K. M., Goodman, S. A., Bailey, E. M., and Lothrop, C. D., Jr. (1994). The molecular basis of canine pyruvate kinase deficiency. Exp. Hematol. 22:866.

Winterø, A. K., Fredholm, M., and Thomsen, P. D. (1991). Variable (dG-dT) $)^{n}-(d C-d A)_{n}$ sequences in the porcine genome. Genomics 12:281.

Yuzbasiyan-Gurkan, V., Wagnitz, S., Blanton, S. H., and Brewer, G. J. (1993). Linkage studies of the esterase $\mathrm{D}$ and retinoblastoma genes to canine copper toxicosis: a model for Wilson disease. Genomics 15:86. 